\title{
Neurology in the United Kingdom. II: a study of current neurological services for adults
}

\author{
R Langton Hewer, V A Wood
}

\begin{abstract}
Health care planning relies on accurate data, yet there are few published data on neurological services in the United Kingdom. This paper describes the number and distribution of consultant neurologists in the UK and is based on a questionnaire completed by Regional Health Authorities and their equivalents, by Special Health Authorities, and by regional representatives of the Association of British Neurologists. The data were published by the $A B N$ in 1988 but have not previously been widely available. The study identified 190 consultant neurologists (152 whole time equivalents). Overall there was one whole time neurologist for 373000 persons but the ratio varied by a factor of four in different regions. There was a wide variation in the distribution of consultant neurological sessions between Health Districts. One group of neurologists was based in centres. A second group spent most of their time within the Health District, but had an attachment to a Regional Centre.
\end{abstract}

Acute neurological disease has been shown to account for about $20 \%$ of admissions to medical wards. ${ }^{1}$ Stroke, epilepsy, transient cerebral ischaemic attacks, head injury, meningitis, and polyneuritis are examples of some of the acute disorders encountered. Chronic neurological diseases, including stroke, multiple sclerosis, Parkinson's disease, and motor neuron disease, represent a substantial burden of disability. A recent paper ${ }^{2}$ has shown that a population of a quarter of a million will contain about 5000 people with disabling neurological disease, of whom 1500 will be severely disabled.

The epidemiological position described above indicates that neurological disease and its sequelae represents a major commitment for the National Health Service (NHS), with a significant workload in every Health District.

In September 1986, 178 consultant neurologists were reported to be in post in England and Wales, ${ }^{3}$ but their geographical distribution was not published. In 1984 Hopkins wrote an article entitled "Different Types of Neurologist". In the correspondence that followed in the British Medical Journal considerable dissatisfaction was expressed about the availability of neurological expertise in various parts of the country.

There are two essential components of every clinical service- quality and availability. This paper addresses the second issue as applied to clinical neurology. The study was undertaken with the collaboration of the Services Sub-Committee of the Association of British Neurologists (ABN), and specifically addresses the following areas:

1) The number and distribution of consultant neurologists working in the UK, and the relationship with population density.

2) The number and distribution of weekly NHS neurology sessions in the UK, and the relationship with population density in the Health Districts of England and Wales.

3) The number and distribution of NHS neurology outpatient clinics in the UK.

4) The number and distribution of Neurological Centres in the UK, and the number of neurology sessions held in areas where centres are sited.

\section{Method}

For the purposes of this study, a neurologist is defined as a consultant with a contract in clinical neurology. We have not included general physicians with an interest in neurology, paediatric neurologists, consultants in spinal injury, or consultants having contracts in allied disciplines such as neurophysiology or neuropathology. Sessions in rehabilitation have been counted as neurology sessions, provided that the consultant concerned also has a contract in clinical neurology.

A full time NHS contract is 11 sessions (5.5 days). Consultants are contracted by Regional Health Authorities (RHA) to work on a sessional basis in one or more Health District. Some consultants are employed by the NHS on a part time basis, having less than 11 contracted NHS clinical sessions. To determine the number of whole time equivalent (WTE) neurologists working in each Health Region, we have divided the total number of NHS sessions worked by 11 .

Some consultant neurologists have academic sessions. We have separately collected data on the number of academic sessions held by consultants. Academic sessions are not designated for patient care. A neurological centre is defined as a hospital in which neurologists and neurosurgeons work together, having their own beds 
and junior staff. We have not investigated centres where neurologists have their own beds and junior staff but neurosurgery is not included.

Information was obtained from two sources:

\section{REPRESENTATIVES OF THE ASSOCIATION OF} BRITISH NEUROLOGISTS

The $A B N$ representatives were each sent a questionnaire asking for a list of all consultant neurologists working in their region, in June 1987, and the total number of NHS and academic neurology sessions worked by each neurologist, each week. Sessions were assigned to the Regions where they were actually worked. The representatives were also asked for the names and location of all neurological centres in the Region.

\section{HEALTH AUTHORITIES}

The UK is divided into Health Districts or Boards (all termed districts in this paper). In addition, London postgraduate teaching hospitals are established as Special Health Authorities (SHAs). Regional Health Authorities and their equivalents (all termed RHAs in this paper) are responsible for a number of districts. RHAs and SHAs were asked to complete a questionnaire indicating the number of NHS Consultant Neurological sessions allocated to each constituent Health District each week in June 1987) and the number of neurology outpatient clinics held in 1986 (calendar year). After the original questionnaires were returned, raw data were returned to source for checking on at least two occasions.

\section{Results}

NUMBER OF CONSULTANT POSTS IN NEUROLOGY The number of consultant posts in neurology in the UK identified in this study was 190 . This number included three vacant posts, one locum post, and six consultants who each held 11 academic sessions each week. Fifty six consul- tants held full time NHS posts (11 sessions/ week).

The number of whole time equivalent (WTE) neurologists, based on NHS clinical sessions, in the UK was $152 \cdot 3$. In addition, 50 consultants held between them a total of 238 academic sessions, representing 21.6 WTEs.

The number of neurologists working in the Health Regions of England and Wales varied from five in East Anglia to 27 in North East Thames; four worked in Northern Ireland and 16 in Scotland.

Sixty one academic sessions were with the Special Health Authorities in London and a further 55 academic sessions were held by the four London Thames Regions (49\% of the UK total of academic sessions were held in London). Two neurologists held between them a total of 10 sessions in Rehabilitation.

The population and number of neurologists (WTE) in each Region, together with the ratio of population to neurologists, is given in table 1 (based on data supplied by $A B N$ representatives). The ratio calculations for the four Thames Regions include neurologists (WTE) working at the Special Health Authorities in London. Although there is a general relationship between population and number of neurologists (WTE) in each Region, there is a considerable disparity between the best provided Region-North East Thames, with a ratio of one WTE neurologist per 157000 population-and the least well provided Region, Trent, with a ratio of one WTE neurologist per 626000 population.

DISTRIBUTION OF NEUROLOGY SESSIONS

The Health Districts of England and Wales vary in size, ranging from a population of 84900 in Rugby (West Midlands Region) to a population of 875000 in Leicestershire (Trent Region). The size of the Health Boards of Scotland range from a population of 19239 in Orkney to 960000 in Greater Glasgow, and in Northern Ireland the population range is 256800 in the Western Health and Social

Table 1 Population and number of neurologists working in health regions (Based on data obtained from ABN representatives and $S H A s$ )

\begin{tabular}{|c|c|c|c|}
\hline Health Region & Population $\star(M)$ & WTE $\dagger$ neurologists & $\begin{array}{l}\text { Ratio population to } \\
W T E \text { neurologist }(\times 1000)\end{array}$ \\
\hline \multicolumn{4}{|c|}{ (+ SHA's) } \\
\hline $\begin{array}{l}\text { NE Thames } \\
\text { NW Thames } \\
\text { SW Thames } \\
\text { SE Thames }\end{array}$ & $\begin{array}{l}3.77 \\
3.49 \\
2.97 \\
3.62\end{array}$ & $\begin{array}{cl}18 \cdot 5 & (5 \cdot 5) \\
10 & (2 \cdot 3) \\
8 \cdot 7 & (0) \\
8 \cdot 7 & (1 \cdot 6) \\
\end{array}$ & $\begin{array}{l}157 \ddagger \\
284 \ddagger \\
341 \ddagger \\
351 \ddagger\end{array}$ \\
\hline Special HAs & & $9 \cdot 4 \quad(9 \cdot 4)$ & \\
\hline $\begin{array}{l}\text { North Western } \\
\text { South Western } \\
\text { East Anglia } \\
\text { West Midlands } \\
\text { Yorkshire } \\
\text { Oxford } \\
\text { Northern } \\
\text { Wessex } \\
\text { Mersey } \\
\text { Trent } \\
\text { Wales } \\
\text { Total England \& Wales } \\
\text { Scotland } \\
\text { N Ireland }\end{array}$ & $\begin{array}{l}3.99 \\
3.18 \\
1.99 \\
5.18 \\
3.6 \\
2.48 \\
3.08 \\
2.88 \\
2.41 \\
4.63 \\
2.82 \\
50.09 \\
5.13 \\
1.56\end{array}$ & $\begin{array}{c}10 \cdot 6 \\
8 \cdot 3 \\
5 \\
13 \\
8 \cdot 9 \\
5 \cdot 6 \\
6 \cdot 8 \\
6 \\
4 \cdot 4 \\
7 \cdot 4 \\
4 \cdot 8 \\
136 \cdot 1 \\
12 \cdot 7 \\
3 \cdot 5\end{array}$ & $\begin{array}{l}376 \\
383 \\
398 \\
398 \\
404 \\
443 \\
453 \\
480 \\
548 \\
626 \\
588 \\
368 \\
404 \\
446\end{array}$ \\
\hline Grand Total UK & $56 \cdot 78$ & $152 \cdot 3$ & 373 \\
\hline
\end{tabular}

^Hospital Year Book, 1988.

+Calculated by dividing number of NHS sessions worked by 11 (a full time contract).

$\ddagger$ Calculations for the Thames Regions includes consultants working at SHAs. 
Table 2 Number and distribution of weekly NHS neurology sessions (Based on data obtained from RHAs and SHAs)

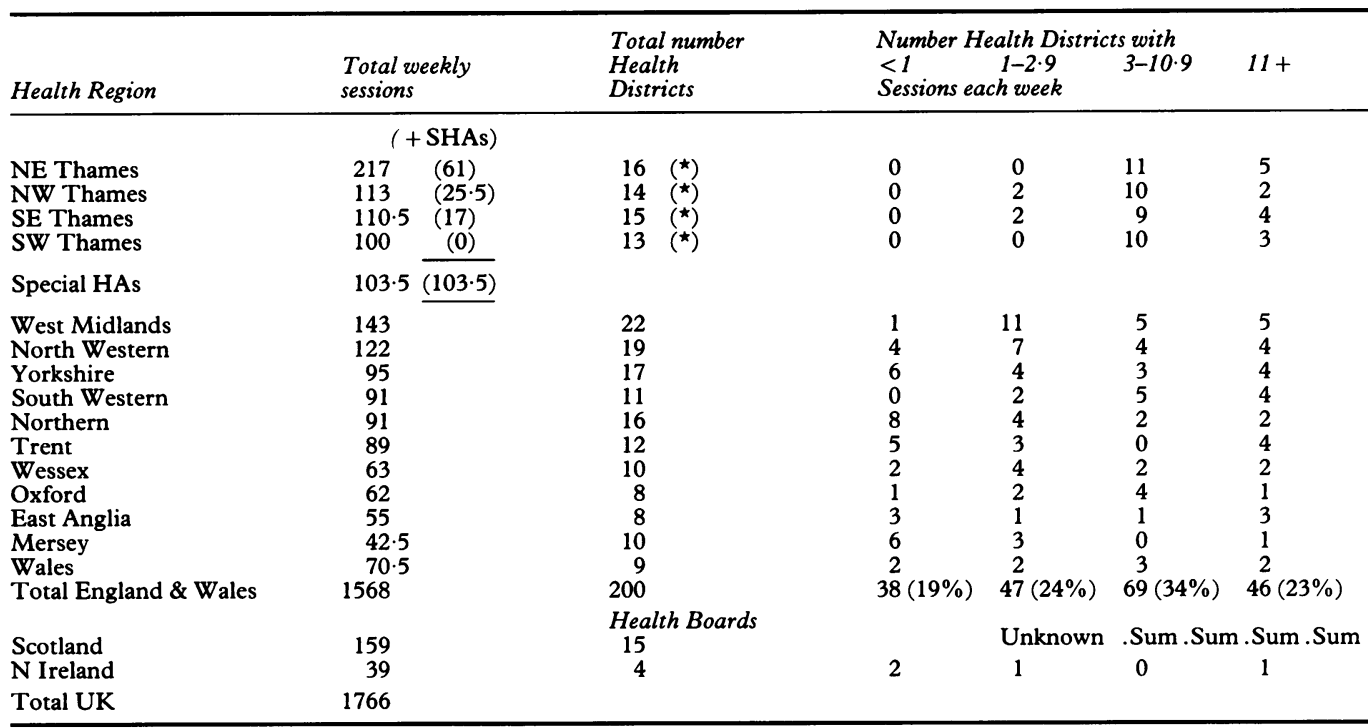

$\left.{ }^{\star}{ }^{\star}\right)$ Calculations for the Thames Regions include sessions at SHAs.

Services Board to 642100 in the Eastern Health and Social Services Board.

We found a trend for the larger Districts to have more neurology sessions: $31(27 \%)$ Health Districts with a population of less than 251000 have less than one neurology session each week ( 18 have 11 or more sessions), while only seven (8\%) Districts with a population of 251000 and over have less than one neurology session each week (28 have 11 or more sessions).

The number of NHS neurology consultant sessions held in the UK is set out in table 2. No reliable data were available for Scottish Health Boards. Again, analyses for the Thames Regions include sessions held at the SHAs. It can be seen that, while $46(23 \%)$ of the 200 Health Districts in England and Wales have 11 or more weekly neurology sessions, $85(43 \%)$ have less than three, including $38(19 \%)$ which have less than one weekly neurology session.

The distribution of Neurology services within Health Regions is uneven. For example, in Oxford Region (population 2.48 million) only one out of eight Health Districts (13\%) has less than one weekly neurology session, while in Mersey Region (population 2.41 million) six out of 10 Health Districts (60\%) have less than one neurology session each week.

Table 3 shows the number of people living in the Health Districts with less than one weekly neurology session. Overall, in England and Wales $7 \cdot 1$ million people live in these Health Districts.

\section{NUMBER AND DISTRIBUTION OF NEUROLOGY} OUTPATIENT CLINICS

Table 4 (based on data from RHAs) shows the total number of clinics held in each Region in 1986 (excluding any held in the SHAs). The total held in the UK was 27067 (or 541 per week); indicating that $31 \%$ of weekly neurology sessions (see table 2) were spent in outpatient clinics. Table 4 also indicates the number of clinics held in each Health District in England and Wales in 1986 . While $30.5 \%$ of Health Districts in England and Wales had three or more clinics each week, $33 \%$ had less than one and $14 \%$ had none at all.

Again, it can be seen that the geographical deployment of services varies-in the Northern and Mersey Regions about $80 \%$ of Health Districts had less than one weekly outpatient

Table 3 Number of people living in health districts with less than one weekly neurology session (Based on data obtained from RHAs and Hospital Year Book, 1988)

\begin{tabular}{llc}
\hline & $\begin{array}{l}\text { Population of all Health Districts with less than } \\
\text { Health Region }\end{array}$ & weekly neurology session $(M)$ \\
\hline NE Thames & 0 & $(\%$ of Region's total population) \\
NW Thames & 0 & $(0)$ \\
SE Thames & 0 & $(0)$ \\
SW Thames & 0 & $(0)$ \\
South Western & 0 & $(0)$ \\
West Midlands & $0 \cdot 3$ & $(5)$ \\
Oxford & $0 \cdot 2$ & $(7)$ \\
Wessex & $0 \cdot 4$ & $(13)$ \\
North Western & $0 \cdot 8$ & $(20)$ \\
East Anglia & $0 \cdot 5$ & $(25)$ \\
Trent & $1 \cdot 2$ & $(30)$ \\
Yorkshire & $1 \cdot 1$ & $(41)$ \\
Mersey & 1 & $(46)$ \\
Northern & $1 \cdot 4$ & $(7)$ \\
Wales & $0 \cdot 2$ & $(14)$ \\
Total England \& Wales & $7 \cdot 1$ & \\
& Health Boards & $(43)$ \\
Scotland & Unknown & \\
N Ireland & $0 \cdot 7$ &
\end{tabular}


Table 4 Number and distribution of NHS neurology clinics (Based on data obtained from RHAs)

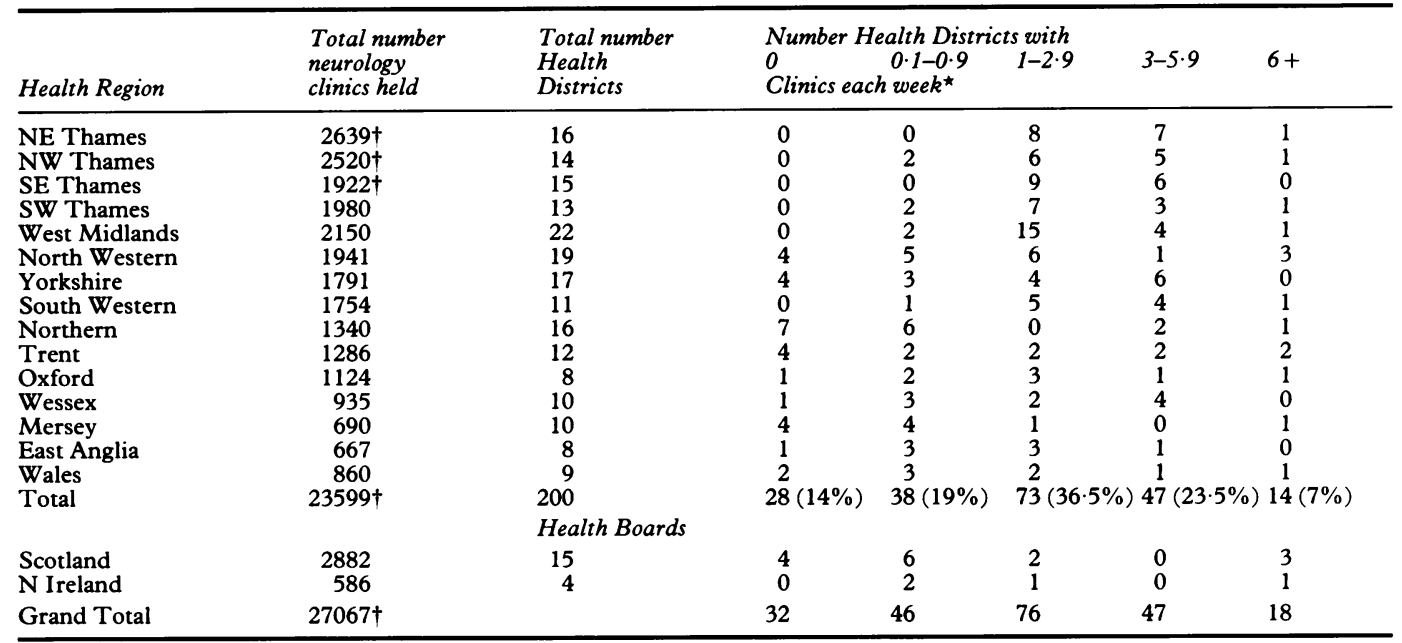

*Calculated by dividing total number of clinics held in each Health District in 1986 by 50 .

tData do not include clinics held in SHAs.

clinic, while in the North East and South East Thames Regions all Health Districts had at least one clinic each week.

\section{NUMBER AND DISTRIBUTION OF NEUROLOGICAL CENTRES}

The number of centres with both neurological and neurosurgical facilities in each Health Region is shown in table 5 . In total there are $\mathbf{4 0}$ neurological/neurosurgical centres in the UK and every Region has at least one (range 1-5).

Nineteen per cent of the total population of England and Wales live in Health Districts in which Centres are sited. Fifty six per cent of consultant sessions are held in these Districts. Table 5 demonstrates that there is a disparity between the number of consultant sessions held in Health Districts and the density of population. For example, in the South Western Region $17 \%$ of the population live in the two Health Districts in which Centres are sited and $33 \%$ of sessions are allocated to those Health Districts. By comparison, in Mersey Region
$7 \%$ of the population live in the Health District in which the Centre is sited and $86 \%$ of consultant sessions are held in this Health District.

\section{Discussion}

In any organisation, every level of planning (that is, strategic, tactical and operational) is dependent upon reliable data, which should be updated at regular intervals. In the NHS, lack of planning might result in ineffective patient care and the inefficient use of resources.

Following the formulation and implementation of plans, progress should then be monitored and this will require the setting of standards as a basis for evaluation.

\section{RELIABILITY OF DATA}

We were hampered by the difficulties encountered in obtaining credible information about neurology services and, before discussing the findings of the study, it is important to examine the accuracy of the data.

Table 5 NHS sessions held in Districts where neurological centres are located

\begin{tabular}{|c|c|c|c|c|}
\hline Health Region & Number of Centres $\star$ & $\begin{array}{l}\text { \% Region's total } \\
\text { population living inside } \\
\text { Districts with centre }\end{array}$ & $\begin{array}{l}\text { Number weekly sessions } \\
\text { held inside Districts } \\
\text { with centre }\end{array}$ & $\begin{array}{l}\text { (\% of } \\
\text { total } \\
\text { sessions } \dagger)\end{array}$ \\
\hline & $(+S H A s)$ & \multicolumn{3}{|c|}{$(+S H A s)$} \\
\hline $\begin{array}{l}\text { SE Thames } \\
\text { SW Thames } \\
\text { NW Thames } \\
\text { NE Thames }\end{array}$ & $\begin{array}{ll}1 & \text { (Maudsley) } \\
2 & \\
1 & \text { (Maida Vale) } \\
5 & \text { (National) }\end{array}$ & $\begin{array}{r}12 \\
16 \\
8 \\
28\end{array}$ & $\begin{aligned} 18 & (17) \\
38 & (0) \\
43 & (29) \\
145 & (45 \cdot 5)\end{aligned}$ & $\begin{array}{l}(31) \\
(40) \\
(53) \\
(72)\end{array}$ \\
\hline Special HAs & 3 (3) & - & $91.5(91.5)$ & - \\
\hline $\begin{array}{l}\text { East Anglia } \\
\text { South Western } \\
\text { Wessex } \\
\text { Trent } \\
\text { Oxford } \\
\text { Yorkshire } \\
\text { West Midlands } \\
\text { North Western } \\
\text { Northern } \\
\text { Mersey } \\
\text { Wales } \\
\text { Total England and Wales }\end{array}$ & $\begin{array}{r}1 \\
2 \\
1 \\
2 \\
1 \\
3 \\
4 \\
4 \\
2 \\
1 \\
2 \\
35\end{array}$ & 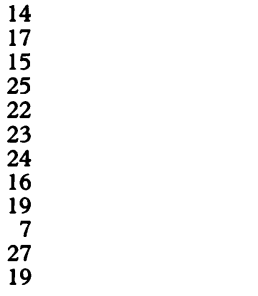 & $\begin{array}{l}18 \\
30 \\
28 \\
47 \\
38 \\
58 \\
91 \cdot 5 \\
91 \\
73 \\
36 \cdot 5 \\
48 \\
894 \cdot 5\end{array}$ & $\begin{array}{l}(33) \\
(33) \\
(44) \\
(53) \\
(61) \\
(61) \\
(64) \\
(74) \\
(81) \\
(86) \\
(68) \\
(57)\end{array}$ \\
\hline \multicolumn{5}{|c|}{ Health Boards } \\
\hline $\begin{array}{l}\text { Scotland } \\
\text { N Ireland }\end{array}$ & $\begin{array}{l}4 \\
1\end{array}$ & $\begin{array}{l}51 \\
41\end{array}$ & $\begin{array}{l}\text { Unknown } \\
149\end{array}$ & (94) \\
\hline Total UK & 40 & & & \\
\hline
\end{tabular}

^Defined as hospital in which neurologists and neurosurgeons work together.

tIncluding sessions worked at SHAs. 
Some difficulty was encountered in determining the exact number of consultant neurology sessions. Difficulties were particularly marked where there were split appointments, for example between the Special Health Authorities in London and one or more Metropolitan Health Authorities, or where consultants worked in more than one Health Region.

There was some disparity between the number of sessions identified by the $A B N$ Representatives and the RHAs. Two RHAs subsequently confirmed that sessions may be "allocated" to various Health Districts by them, but allocation did not necessarily mean that sessions were "worked". Our results relating to the distribution of neurological sessions across Health Districts are based on data supplied by RHAs and therefore describe the situation associated with "allocated" rather than "worked" sessions. We were surprised when three Regions informed us that consultants working 10 sessions (and being paid $10 / 11$ ths) are entered on statistical returns as being employed for 11 sessions!

It is interesting to relate the number of sessions allocated by each Health Region to the actual number of consultant neurologists working in them. Overall, $128(69 \%)$ consultants with NHS contracts are employed for less than 11 sessions per week-61 $(33 \%)$ for less than 10. It appears that in some Regions more clinical sessions are allocated than could realistically be worked. For example, in the Northern Region the RHA allocated 91 sessions - there were 10 consultants working in this Region and one had a two session NHS commitment only; four consultants worked 11 NHS sessions, one 10 NHS sessions, and one had a full time academic contract. The other three consultants held part clinical/part academic posts (split $6 / 5,7 / 4$ ). The information supplied by the $A B N$ representative in the Northern Region indicated that 75 clinical sessions are worked.

It also became apparent, during discussions with neurologists in different parts of the UK, that some academic sessions were being allocated for NHS work, and the converse also sometimes occurred.

The Department of Health reported in Health Trends $(1987)^{3}$ that 178 Consultant neurologists were in post in England and Wales in September 1986. Our study identified 164 consultants in England and Wales in June 1987, plus six full time academic posts. Enquiry with two RHAs confirmed that each Region supplies the Department of Health with information on the number of consultants employed. If consultants are employed by two Health Regions it is possible that they could be counted twice. Excluding consultants working in a Region plus a SHA, we identified 14 consultants who worked NHS clinical sessions in two Health Regions. If we had counted these 14 consultants twice then this would have been a total of 178 consultants in England and Wales.

In presenting the results we had a particular difficulty with the London information. There is a concentration of resources in the middle of the city and some of these are situated in the SHAs. The dilemma concerned the question of whether or not the data relating to the SHAs should be presented separately from that of the RHAs. We eventually decided to include sessions held at the SHA hospitals within the appropriate Regional figures. For example, the NE Thames Region had one full time neurologist for 204000 persons, but if sessions held in the SHA are included the figure becomes one full time neurologist to 157000 persons. In our view, exclusion of SHA resources in the Thames Regions would have distorted the figures and produced a misleading picture of the neurology staffing situation in the metropolis.

\section{NUMBERS OF NEUROLOGISTS: INTERNATIONAL COMPARISONS}

When examining the results of the study it is important to bear in mind that the data relate to June 1987. In some Health Authorities consultant staffing changes have occurred since that date.

Initially it is necessary to discuss the number of consultant posts in clinical neurology. In some specialties consultants practise both in general medicine and in a specialty. However, only nine out of 1142 general physicians in England, Wales and Northern Ireland have a declared particular interest in neurology and in only four instances was this interest incorporated into the consultants' contracts. ${ }^{5}$ There were 164 consultant neurologists in post in England and Wales identified in this study (plus six full time academic appointments). The total number of consultants with a sole, or partial, interest in neurology is low compared with other medical specialties for example, there were 267 cardiologists, 349 endocrinologists, and 286 gastroenterologists in England and Wales in 1986, including those practising the pure specialty and those practising it as a second specialty. ${ }^{3}$

It is also interesting to compare the number of neurologists in the UK with that in other Western countries. We are not aware of any published data on this matter. We have, however, made personal enquiries in eight European countries and in the United States. The number of neurologists in every instance exceeds those per unit of population in the UK by a factor of at least six. The number of neurologists in the UK is therefore also low in comparison with international standards. This situation is compounded by the fact that most countries have a substantial number of specialists in rehabilitation who are, presumably, involved in the care of patients with chronic neurological diseases. There are very few consultants in rehabilitation in England and Wales and none are listed in the recent Health Trends article. ${ }^{3}$

\section{FUTURE EXPANSION}

How many consultant neurologists will be needed in the future? The ABN has undertaken extensive discussions within its specialty about the future development of clinical neurology, 
and a Statement of Intent was agreed at the Annual General Meeting in April 1988..$^{6}$ The Association recommended that there should be at least one WTE neurologist per 200000 persons. ${ }^{6}$ This would give a figure of $284 \mathrm{WTE}$ neurologists in the UK. We have identified 152 WTEs (excluding academic sessions) - giving a shortfall of 132 full time posts overall.

Recent figures for consultant neurologist posts in England and Wales ${ }^{3}$ show that only 19 new consultant posts were created between 1981-86, giving an annual growth rate of four posts $(2.5 \%)$. At this level of expansion it would take 33 years (until the year 2021) to reach the $A B N$ recommended level of one WTE neurologist per 200000 persons. Even this calculation assumes that all new appointees would have a full time contract and that the population of the UK will remain static - both are unlikely. An increase of about $87 \%$, or more, in the number of consultant neurologists is unlikely to occur without a major Department of Health initiative.

Even if a considerable expansion of the consultant neurologist establishment were to occur during the next few years, the majority of patients with neurological symptoms, and many with serious neurological disease, would probably continue to be dealt with by nonneurologists-notably general practitioners and general physicians. It is essential therefore that their neurological training should enable them to handle neurological problems appropriately.

\section{DISTRIBUTION OF NEUROLOGISTS}

This study has shown wide variation in the distribution of consultant neurological sessions between Health Districts. For example, only $22 \%$ of Health Districts in England and Wales had the equivalent of one WTE neurologist (11 sessions per week), or more. At the other end of the scale, $19 \%$ of Health Districts had less than one neurological session each week, and no clinics were held in $14 \%$ of Health Districts.

The variation between Health Districts is, to some extent, explained by the proportion of consultant sessions held in the Districts in which neurological centres are sited. In fact, two different models of provision have been identified in this study: the "Centre-based" approach as exemplified by Mersey and Northern Regions, and the "District-based" approach adopted by, for example, East Anglia and the South Western Regions.

Table 6 Incidence and prevalence of neurological disease in 38 UK health districts with little or no local neurological service

\begin{tabular}{lccc}
\hline & $\begin{array}{c}\text { Incidence } \\
\text { (patients per year) }\end{array}$ & Prevalence & \\
\cline { 3 - 4 } & 1278 & 11360 & 9713 \\
\hline Parkinson's disease & 284 & 7100 & 3550 \\
Multiple sclerosis & 142 & 426 & 398 \\
Motor neuron disease & 4970 & 110760 & $36920^{\star}$ \\
Epilepsy & 15620 & 42600 & 25560 \\
Stroke & 14200 & - & 21300 \\
Head injury & 1136 & 3209 & 1136 \\
Cerebral tumour & 1065 & 3550 & - \\
Subarachnoid haemorrhage & 2130 & 10650 & - \\
Transient ischaemic attacks & 2840 & - & - \\
Polyneuropathies & & \multicolumn{2}{c}{} \\
\hline
\end{tabular}

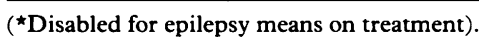

We have calculated that $14 \%$ of the population of England and Wales ( $7 \cdot 1$ million persons) live in the 38 Health Districts with less than one weekly consultant neurological session. For practical purposes these Health Districts probably have little in the way of "Districtbased" services.

A major study of the epidemiology of neurological disease was undertaken by Brewis et $\mathrm{al}^{7}{ }^{7} \mathrm{Kurtzke}^{8}$ reviewed the published literature, and a recent review contained a more detailed analysis. ${ }^{2}$ Using this published literature, we have estimated the number of patients with serious neurological disease who live in the 38 Districts with little or no local neurological services (table 6).

The burden of neurological disease in any community is substantial and it would be unrealistic to suggest that all neurological disease should be dealt with by neurologists. We would, however, strongly argue that there should be ready access to neurological expertise throughout the country, and this was recognised in the recent ABN Statement of Intent. ${ }^{6}$

There has been little public debate on the minimum neurological provision for a Health District. Such provision should include the availability of on-site advice regarding the diagnosis and management of neurological emergencies, outpatient consultations, ward referrals, and the operation of a service for patients with chronic disabling neurological disease. It is important that enough sessions should be available in each Health District to meet these criteria. At the same time each neurologist should have a firm link with a neurological centre.

To some extent the different approaches to the provision of neurological services may be justified by variations in population density. Nonetheless, an evaluation of the two models of service provision (that is, "Centre-based" versus "District-based" approaches) at present practised in the UK would seem desirable.

\section{Conclusions}

Three main conclusions are drawn from this study:

1 There appears to be a good case for a substantial increase in the number of consultant neurologists in the UK. We have already pointed out the current low level of expansion of the specialty.

2 It is important to ensure that all persons with neurological disease have reasonable access to neurological expertise, wherever they live.

3 There is a need to evaluate different ways of providing medical services.

The basic standards of neurological provision are now emerging. The question arises as to who will provide the impetus for action to ensure that the standards are met. The Department of Health has not, as far as we are aware, indicated whether it has a view on the matter. The charitable organisations, such as the Multiple Sclerosis Society, the Parkinson's Disease Society, the Kings Fund, and others, could have an important influence.

Finally, we would again emphasise the 
importance of collecting and presenting reliable data relating to clinical services. In this way the strengths and weaknesses of clinical provision can be identified and a logical basis for strategic planning created.

We gratefully acknowledge the help we have received from members of the Services Sub-Committee of the ABN and from the Regional Health Authorities, who supplied data. Also to Esther Crow who helped collate the data and Dr Nicholas Kent for his work on the epidemiology of neurological disease. Acknowledgement and thanks is also particularly extended to Professor John Colley, Department of Epidemiology and Community Medicine, Bristol University, for his considerable assistance and support.
1 Morrow JI, Patterson VH. The neurological practice of a district general hospital. J Neurol Neurosurg Psychiatry 1987;50:1397-1401.

2 Wade DT, Langton-Hewer R. The epidemiology of some neurological diseases. Int Rehabil Med 1987;8:129-37.

3 Medical Manpower and Education Division, DHSS. Medical and dental staffing prospects in the NHS in England and Wales in 1986. Health Trends 1987;19:1-7.

England and Wales in 1986. Health Trends 1987;19:1-7.;
4 Hopkins A. Different types of neurologist. BMJ 1984; 288:1733-6.

5 Davidson C, King RC. General medicine in the eighties. $B M J 1986 ; 293: 547-50$

6 Association of British Neurologists. Statement of Intent, 1988.

7 Brewis M, Poskanzer DC, Rolland C, et al. Neurological disease in an English city. ACTA Neurol Scand 1966;42:Supp 42.

8 Kurtzke JF. The current neurologic burden of illness and injury in the United States. Neurology 1982;32:1207-14. 